\title{
Engeland
}

\section{Een leven zonder legitieme? Erfrecht in Engeland en Wales}

Drs. M.R. Beuker*

\section{Inleiding}

Een blik op het erfrecht van Engeland en Wales biedt vaak verrassende perspectieven, omdat het recht zich daar op vele punten onderscheidt van de rechtsstelsels zoals die gelden in de rest van West-Europa. ${ }^{1}$ Een gebied waar dit verschil tussen civil law en common law in het bijzonder duidelijk wordt, betreft de bescherming van nabestaanden. ${ }^{2}$ Het is dit onderdeel dat in deze bijdrage dan ook centraal staat. Eerst wordt kort ingegaan op de positie van de langstlevende echtgenoot in het intestaaterfrecht. De meeste aandacht gaat vervolgens uit naar erfrechtelijke aanspraken van de langstlevende echtgenoot en andere nabestaanden die niet erven volgens testament of, indien toepasselijk, intestaaterfrecht.

Drs. M.R. Beuker is promovendus notarieel recht aan de Rijksuniversiteit Groningen.

1. In de rest van deze tekst wordt gemakshalve gesproken over het erfrecht van Engeland, maar hiermee wordt ook het erfrecht van Wales bedoeld.

2. Verschillen zitten niet alleen in de inhoud van het materiële recht, maar ook in de wijze waarop nalatenschappen worden afgewikkeld. Een evenbeeld van de bij ons bestaande 'Latijnse' notaris ontbreekt in Engeland. Daar zal altijd een personal representative (een executor of een administrator) worden aangesteld op wie de nalatenschap vererft en die de nalatenschap na voldoening van de schulden doet toekomen aan de erfgenamen.

\section{De langstlevende echtgenoot in het intestaaterfrecht}

Het erfrecht bij versterf wordt voornamelijk geregeld door de Administration of Estates Act 1925. ${ }^{3}$ Indien een langstlevende echtgenoot of geregistreerde partner achterblijft, verkrijgt de langstlevende de gehele nalatenschap indien deze een waarde vertegenwoordigt van minder dan 250.000 pond. Indien de nalatenschap groter is, verkrijgt de langstlevende 250.000 pond, evenals alle personal chattels en de helft van de rest van de nalatenschap. ${ }^{4}$ Onder personal chattels worden diverse roerende goederen verstaan die de overledene gebruikte voor niet-zakelijke activiteiten. ${ }^{5}$ In de situatie waarin de erflater naast de langstlevende echtgenoot of geregistreerde partner geen nageslacht achterlaat, verkrijgt de langstlevende de gehele nalatenschap. ${ }^{6}$

Bij kleine nalatenschappen biedt het Engelse erfrecht dus een sterkere positie aan de langstlevende dan de Nederlandse wettelijke verdeling. De langstlevende verkrijgt in dat geval immers de gehele nalatenschap en de kinderen krijgen zelfs geen niet-opeisbare vordering. Bij grotere nalatenschappen kan de langstlevende echter niet profiteren van een systeem dat vergelijkbaar is met de Nederlandse wettelijke verdeling. De kinderen ver-

3. Zie voor een uitgebreide beschrijving van het intestaaterfrecht B. Sloan, Borkowski's Law of Succession (3de druk), Oxford: Oxford University Press 2017.

4. S. 46(1) jo. schedule 1A Administration of Estates Act 1925.

5. Gedacht kan worden aan inboedel en auto's. Geld en hetgeen gebruikt werd voor een onderneming vallen buiten dit begrip. Voor een exacte opsomming van wat men moet verstaan onder personal chattels, zie s. 55(1)(x) Administration of Estates Act 1925.

6. S. 46(1) Administration of Estates Act 1925. 
krijgen in Engeland namelijk direct een deel van de nalatenschap waarover zij kunnen beschikken.

Bovenstaand systeem leidt niet tot uitzonderlijk veel procedures; toepassing van deze regels is doorgaans niet ingewikkeld. Tot meer discussie leidt de positie van de onterfde langstlevende. In de rest van dit artikel zal dan ook niet alleen worden gekeken naar de positie van de langstlevende, maar ook naar die van andere nabestaanden die ontevreden zijn vanwege hun onterving of de omvang van het erfdeel dat ze krijgen bij versterf of testament.

\section{Bescherming van nabestaanden in historisch perspectief}

Het Romeinse recht heeft grote invloed uitgeoefend op de erfrechtelijke stelsels van West-Europa. Het is dan ook niet verrassend dat de legitieme portie met haar Romeinsrechtelijke wortels daar een wijdverbreid rechtsfenomeen is geworden. Hoewel inmiddels vele verschillen bestaan tussen de manieren waarop de legitieme portie in de verschillende landen is vormgegeven, blijft een aanspraak voor kinderen in de vorm van een vast gedeelte van de nalatenschap een fundamenteel kenmerk van deze stelsels. ${ }^{7}$

Hoe anders is dat in Engeland. Daar verkreeg het lokale rechtsstelsel, de common law, reeds in de Middeleeuwen exclusieve werking, hetgeen tot gevolg had dat het Romeinse recht niet als subsidiaire rechtsbron gebruikt werd. ${ }^{8}$ Hierin ligt een verklaring voor het feit dat de daar gehanteerde erfrechtelijke beginselen wezenlijk anders zijn dan de onze en de legitieme er geen voet aan de grond heeft gekregen. Dit werpt vragen op omtrent de wijze waarop nabestaanden verzorgd worden die niet in hun eigen behoeften kunnen voorzien.

Ondanks het ontbreken van een legitieme portie bestaan ook in Engeland al sinds de Middeleeuwen voorzieningen voor de bescherming van nabestaanden die niet op grond van testament of intestaaterfrecht verzorgd achterblijven. Het is dan ook een misvatting om te denken dat de common lam in Engeland en Wales gekenmerkt wordt (of werd) door absolute testeervrijheid. Voor echtgenotes bestond bijvoorbeeld sinds het eind van de dertiende eeuw de 'dower', die recht gaf op een derde. ${ }^{9}$ Opmerking verdient echter dat in de praktijk vaak een

7. Over een vergelijkbare vergelijking tussen erfrecht van Engeland en een aantal Europese stelsels: W.D. Kolkman, Dwingend erfrecht in Europa. Pleidooi voor afschaffing van de legitieme portie, in: R.J.C. Flach, G.T. de Jong, R. Koolhoven \& F.J. Vonck (red.), Dwingend privaatrecht op maat, Groningen: Groningen Centre for Law and Governance 2015, p. 73 e.v.

8. J.H.A. Lokin \& W.J. Zwalve, Hoofdstukken uit de Europese codificatiegeschiedenis, Den Haag: Boom Juridische uitgevers 2006, p. 356-367.

9. E. Spring, Law, land and family, Michigan: University of North Carolina Press 1993, p. 40 manier werd gevonden om 'dwingendrechtelijke' aanspraken te ontwijken. In de achttiende eeuw werd de uitoefening van dit recht door het veelvuldig gebruik van 'strict settlements' praktisch illusoir. ${ }^{10}$

De wetgever heeft vanwege de mogelijkheden die bestonden om dwingende aanspraken uit de weg te gaan, na hevig debat wijzigingen doorgevoerd om de bescherming van nabestaanden te vergroten. In 1938 gaf hij de rechter met de invoering van de Inheritance (Family Provision) Act 1938 bevoegdheden om testamentaire beschikkingen te negeren. ${ }^{11}$ In 1975 werd de omvang van deze bevoegdheden aanzienlijk vergroot met de invoering van de Inheritance Act 1975. Op de inhoud van laatstgenoemde wet zal hierna worden ingegaan.

\section{Beperkingen van de testeervrijheid}

In beginsel is een erflater vrij om over zijn nalatenschap te beschikken zoals hem goeddunkt. Daarop is echter een aantal beperkingen aangebracht. Zo bestaat in Engeland het concept van de proprietary estoppel, waarbij niet-nagekomen beloftes van een erflater om iemand iets na te laten in bepaalde gevallen toch kunnen worden afgedwongen. ${ }^{12}$ Het gaat dan om gevallen waarin de teleurgestelde nabestaande nadeel heeft ondervonden doordat hij op een bepaalde manier handelde in de verwachting gecompenseerd te worden voor zijn werk. Het uitvoeren van onbetaalde zorgtaken biedt hiervan een goed voorbeeld.

De belangrijkste beperking van de testeervrijheid wordt echter gevormd door de eerdergenoemde Inheritance Act 1975. Een bepaalde relationele verhouding tot de erflater leidt daarin, in tegenstelling tot bij de legitieme portie, echter niet automatisch tot een aanspraak; de testamentaire beschikkingen of de intestaatregels gelden, tenzij een specifieke voorziening wordt verzocht aan en toegekend door de rechter.

Het beoordelen van deze claims gebeurt in twee stappen. Als eerste wordt beoordeeld of reasonable financial provision aanwezig is voor degene die zich op de wet beroept. Ook als het intestaaterfrecht van toepassing is, kan de rechter oordelen dat geen reasonable financial provision aanwezig is. Als de rechter concludeert dat dit het geval is, begint de tweede claim, waarin wordt beoordeeld of een voorziening moet worden toegekend en op welke manier dat gedaan moet worden'. Zo'n voorziening wordt enkel toegekend indien de rechter

10. Gedacht kan worden aan 'entails', 'strict settlements' en 'uses'.

11. R.D. Oughton, Tyler's family provision (3de druk), Haywards Heath: Tottel Publishing 1997.

12. J. Mee, Proprietary estoppel and inheritance: Enough is enough?, Conveyancer and Property Lawyer 2013, p. 280-297. Beschikbaar via SSRN: https://ssrn.com/abstract=2317414. 
vaststelt dat geen 'reasonable financial provision' voor de eiser geregeld is.

\section{Het begrip 'reasonable financial provision'}

Rechtspraak maakt duidelijk dat een objectieve uitleg dient te worden gegeven aan het criterium reasonable financial provision. ${ }^{13}$ Dit is niet hetzelfde als het beantwoorden van de vraag of iemand zich al dan niet reasonable heeft gedragen; het is namelijk denkbaar dat een erflater unreasonable heeft gehandeld door iemand (gedeeltelijk) te onterven, maar dat desalniettemin reasonable financial provision voor de nabestaande aanwezig is. ${ }^{14}$ Van de andere kant is het ook mogelijk dat het onterven reasonable was, maar dat gewijzigde omstandigheden waarvan de erflater misschien niet eens op de hoogte was, of waardeontwikkelingen na het overlijden van de erflater, toch hebben gemaakt dat voor die nabestaande geen reasonable financial provision meer aanwezig is. ${ }^{15}$

Voor de langstlevende echtgenoot of geregistreerde partner moet reasonable financial provision worden beschouwd met het oog op alle omstandigheden van het geval whether or not that provision is required for his or her maintenance. ${ }^{16} \mathrm{Om}$ te bepalen wat reasonable is, kan men kijken naar wat de echtgenoot zou hebben gekregen in geval van echtscheiding. Regelmatig wordt in de rechtspraak over de Inheritance Act 1975 dan ook verwezen naar uitspraken over voorzieningen bij scheiding.

Naast de echtgenoot en geregistreerde partner kunnen vele anderen een beroep doen op de Inheritance Act 1975. Daartoe gerechtigd zijn: de niet-hertrouwde voormalige echtgenoot van de erflater, een kind van de erflater, een persoon (anders dan een kind van de erflater) die door de erflater als een kind van de erflater behandeld was in verband met het huwelijk van de erflater, een persoon (niet vallend onder een van de vorige categorieën) die direct voor het overlijden van de erflater geheel of gedeeltelijk onderhouden werd door de erflater, en een persoon anders dan een echtgenoot of voormalige echtgenoot die deel uitmaakte van hetzelfde huishouden als de erflater en als echtgenoot van de erflater gedurende twee aaneengesloten hele jaren direct voor het overlijden van de erflater met hem samenwoonde.

13. Re Coventry, [1980] Ch 461

14. Re Jennings, [1994] Ch 286.

15. Re Hancock, [1998] 2 FLR 346

16. S. 1(2)(a) jo. (aa) Inheritance Act 1975. De in Nederland belangrijke kwestie rondom het woonhuis van de echtgenoten wordt in Engeland vaak niet afgehandeld door het erfrecht. Een goed dat onder joint tenancy gehouden wordt, gaat namelijk volgens het Engels goederenrecht bij overlijden van de ene joint tenant over op de andere(n). Omdat woonhuizen vaak onder joint tenancy gehouden worden, zullen zij vaak buiten de nalatenschap vallen, hetgeen de angel uit het onterven van een echtgenoot kan halen.
De verzoeken van al deze personen worden op grond van de Inheritance Act 1975 beoordeeld aan de hand van een andere maatstaf dan de maatstaf die van toepassing is op echtgenoten en geregistreerde partners. Een beroep wordt namelijk enkel gehonoreerd als zodanige financiële voorzieningen ontbreken als reasonable zouden zijn in alle omstandigheden van het geval for maintenance van de persoon in kwestie. ${ }^{17}$ Deze toets is daarmee strenger dan de toets voor echtgenoten of geregistreerde partners.

\section{Factoren die een rol spelen bij het toekennen van een voorziening}

De wetgever heeft de rechter een aantal gezichtspunten geboden die helpen bij het beoordelen of reasonable financial provision getroffen is (eerste stap), en ingeval die vraag ontkennend beantwoord wordt, welke voorziening dan vastgesteld moet worden (tweede stap). Voor zowel de eerste als de tweede fase van de toets die de Inheritance Act 1975 vereist, heeft de wetgever dezelfde factoren als gezichtspunten gehanteerd.

Ten eerste houdt de rechter rekening met de financiële middelen en behoeften van degene die een voorziening claimt. Niet alleen de middelen en behoeften die bestaan op het moment waarop de claim wordt ingediend, zijn relevant, maar ook die welke waarschijnlijk in de voorzienbare toekomst ontstaan.

Ten tweede houdt de rechter rekening met de financiële middelen en behoeften van anderen die een beroep op section 2 van de Inheritance Act 1975 hebben gedaan. Wederom zijn niet alleen de bestaande, maar ook de waarschijnlijk in de voorzienbare toekomst bestaande middelen en behoeften relevant. Uit het feit dat ook de middelen en behoeften van andere nabestaanden dan de eiser een rol spelen, wordt duidelijk dat een spanningsveld kan bestaan tussen de belangen van personen die een beroep op de Inheritance Act 1975 doen. Blijkens de formulering van de wettekst is niet vereist dat de claims van anderen al vastgesteld zijn. Bij het oordeel over welke voorziening reasonable is, worden dus onzekere toekomstige schulden van de nalatenschap meegewogen. Een andere opvatting zou bovendien onmogelijk zijn, omdat de rechter bij het vaststellen van die andere claims eveneens rekening moet houden met claims die nog niet vastgesteld zijn. Men zou dan terechtkomen in een onoplosbare puzzel omdat geen enkele claim vastgesteld kan worden; één claim zal dus ondanks de onzekerheid over de omvang van andere claims als eerste vastgesteld moeten worden.

Ten derde zijn de financiële middelen en behoeften van begunstigden van de nalatenschap van belang, wederom ook als deze waarschijnlijk in de voorzienbare toekomst

17. S. 1(2)(b) Inheritance Act 1975 
ontstaan. Dit impliceert dat de wetgever het mogelijk heeft geacht dat de testateur behoeften van anderen terecht verkoos boven die van degene die een claim indient. Onzeker is echter welke rol de verhouding tussen erflater en begunstigde heeft. Indien de erflater zijn vermogen zou nalaten aan armen die hij nauwelijks kende, betekent dat dan dat eveneens in financiële nood verkerende kinderen in de kou staan?

Bij het in aanmerking nemen van de financiële middelen van bovenstaande personen houdt de rechter niet alleen rekening met hun inkomens op het moment waarop de rechter oordeelt over de claim, maar ook met hun mogelijkheden om zelf geld te verdienen (section 3(6)). Pensioenvoorzieningen worden eveneens betrokken in de beoordeling van iemands financiële positie, ongeacht of zij hun oorsprong vinden in dienstbetrekking of overheidsvoorziening. ${ }^{18}$ Daarbij verdient opmerking dat het ontvangen van voorzieningen van de overheid niet aan een succesvol beroep in de weg hoeft te staan. ${ }^{19}$

Ten vierde kijkt de rechter naar de verplichtingen en verantwoordelijkheden die de erflater had tegenover degenen die een beroep doen op de Inheritance Act 1975 en degenen die begunstigd zijn door zijn nalatenschap. Hiervoor is niet vereist dat de erflater zijn verplichtingen bij leven nakwam of zijn verantwoordelijkheid nam. Zo kan ook het kind aan wie ten onrechte geen onderhoud verschaft werd toen de erflater leefde, wel een beroep doen op de Inheritance Act 1975. Desalniettemin moeten het wel verplichtingen en verantwoordelijkheden betreffen die de erflater tot zijn overlijden had. Onvervulde verplichtingen en niet-genomen verantwoordelijkheden kunnen niet achteraf uit de nalatenschap worden geëist. ${ }^{20}$

Dit legt een fundamenteel uitgangspunt bloot van de Inheritance Act 1975. Claims worden namelijk niet toegekend voor goed gedrag of omdat een persoon deze verdiende, maar omdat de erflater geen reasonable financial provision voor deze persoon had gemaakt terwijl dat wel nodig was.

Hoewel niet-nagekomen verplichtingen niet achteraf geldend kunnen worden gemaakt, hebben gebeurtenissen die plaatsvonden voor het overlijden van de erflater vaak wel degelijk gevolgen voor de toekenning van een voorziening. Met name wanneer de nalatenschap niet groot genoeg is om alle verplichtingen en verantwoordelijkheden van de erflater na te komen, kan de rechter relevant achten dat een bepaalde persoon heeft geholpen bij het opbouwen van het vermogen van de erflater. ${ }^{21}$ Andere voorbeelden van dit terugkijken worden geboden door rechters die relevant achten dat nalatenschapsgoederen van de erflater voor een groot deel afkomstig waren uit een eerdere erfenis van een ouder van degene die een claim indient op grond van de Inheritance Act $1975^{22}$

Naast de eerdergenoemde vier factoren heeft de wetgever nog drie gezichtspunten gegeven. Dat zijn de omvang en de aard van de nettonalatenschap, fysieke of mentale gebreken van degenen die een beroep op de Inheritance Act 1975 doen en van degenen die begunstigd zijn door de nalatenschap, en tot slot kunnen andere zaken, waaronder het gedrag van degene die een beroep doet op de Inheritance Act 1975 of een andere persoon, relevant zijn.

\section{Ilott v. Mitson: de feiten}

Velen zullen zich bij het lezen van bovenstaande gezichtspunten hebben afgevraagd hoe de rechter al deze factoren moet wegen. Hoe ingewikkeld deze exercitie kan zijn, blijkt uit de Ilott v. Mitson-uitspraak. ${ }^{23}$ Daar ging het om een onterfde dochter die een voorziening claimde in de nalatenschap van haar overleden moeder. De moeder, Mrs Jackson, was vier jaar gehuwd, en zwanger, op het moment dat haar echtgenoot overleed. Het kind zou het enige kind van Mrs Jackson blijken te worden en is eiser in het geding. Zij ging stiekem het huis uit toen ze 17 jaar was om met een door Mrs Jackson afgekeurde vriend samen te wonen. Het gevolg was een vervreemding tussen moeder en dochter, die duurde tot het overlijden van Mrs Jackson, een periode van 26 jaar.

De dochter leefde op het moment van de uitspraak nog met dezelfde jeugdliefde met wie ze op 17-jarige leeftijd was gaan samenwonen. Ze hadden vijf kinderen gekregen en werden niet financieel ondersteund door Mrs Jackson. Ze leefden zelfs vrijwel zonder contact met Mrs Jackson, met wie het contact, ondanks drie pogingen, nooit duurzaam hersteld is. Mrs Jackson besloot dan ook al in 1984 haar dochter te onterven en herhaalde die wens in een nieuw testament in 2002.

Het gezin van de dochter verkeerde in financieel bescheiden omstandigheden. Het huurde een sociale huurwoning. De dochter had geen werk behalve enige administratieve taken die ze voor haar man uitvoerde tegen een vergoeding van 240 pond per jaar. De man verdiende met tijdelijke contracten iets meer dan 4100 pond per jaar. Verder verkreeg de familie inkomen uit diverse overheidsvoorzieningen, zoals kinderbijslag (1878 pond per jaar), een tegemoetkoming voor families met lage inkomens (8112 pond per jaar), een voorziening die vergelijkbaar is met de Nederlandse huurtoeslag en gemeentelijke tegemoetkoming (de laatste twee gezamenlijk ongeveer 5100 pond per jaar).
18. R. Kerridge, Parry and Kerridge: The Law of Succession (13de druk), Londen: Sweet \& Maxwell 2016, p. 176.

19. Re Collins, [1990] Fam 56, 2 All ER 47

20. Re Jennings, [1994] Ch 286.

21. Re Thornley, [1969] 1 W.L.R. 1037
22. Kerridge, Parry and Kerridge: The Law of Succession, p. 177; Re Sivyer, [1967] 1 W.L.R. 1482; Re Styler, [1942] Ch 387, 390; Re Canderton, [1970] 114 S.J. 208; Jelley v. Iliffe, [1981] Fam. 128.

23. Re llott v. The Blue Cross and others, [2017] 2 WLR 979 
De familie had van vergelijkbare bedragen altijd rond kunnen komen, maar de inboedel was oud en er was geen geld om deze te vervangen. De auto had 245 pond gekost en had regelmatig technische problemen. De familie was nooit op vakantie gegaan en kon gezien de financiële omstandigheden geen muzieklessen of sport voor de kinderen betalen.

\section{Ilott v. Mitson: het oordeel van de rechter}

Met deze gegevens was het aan de rechter om te oordelen of reasonable financial provision voor de dochter getroffen was, en indien dat niet het geval was, welke voorziening dan wel getroffen zou moeten worden. Daarbij zou een groot discussiepunt worden dat sommige van de door de overheid verstrekte inkomensbestanddelen van het gezin afhankelijk waren van de omvang van het gezinsvermogen. Als de rechter een grote som geld zou toekennen, zou deze dus mogelijk op kunnen gaan aan het 'reguliere' levensonderhoud. Om dit te voorkomen zou de rechter bijvoorbeeld kunnen bepalen dat de dochter het huis mocht kopen met geld uit de erfenis. De dochter kon haar huurhuis kopen tegen een lagere waarde dan de marktwaarde.

Hoewel eerdergenoemd raamwerk vele gezichtspunten bevat, staat het de rechter vrij ook andere factoren in zijn besluitvorming te betrekken en maakt de wet niet duidelijk welk gewicht aan de verschillende factoren toegekend moet worden. Dat de rechter veel vrijheid heeft, blijkt wel uit de uitspraken die in verschillende instanties gegeven zijn. Als eerste kwamen partijen bij de District Judge. Deze oordeelde dat geen reasonable financial provision voor de dochter getroffen was en kende haar 50.000 pond toe. In hoger beroep bij de Court of Appeal werd echter geoordeeld dat de onterving van de dochter niet leidde tot het ontbreken van reasonable financial provision. Mrs Jackson was met andere woorden niet gehouden een voorziening voor de dochter te treffen. De dochter kreeg niets. Een beroep tegen deze uitspraak van de Court of Appeal was succesvol, omdat de District Judge, in tegenstelling tot wat de Court of Appeal had geoordeeld, noch het recht, noch een rechtsbeginsel verkeerd had toegepast. Een derde rechter, die vervolgens moest oordelen over de omvang van de voorziening, handhaafde de beslissing van de District Judge. Dat leidde opnieuw tot een hoger beroep. Daarin werd aan de dochter een bedrag van 143.000 pond toegekend om het huis te kopen en tevens werd haar het recht toegekend om 20.000 pond op te nemen, eventueel in termijnen. Het is deze beslissing die voorgelegd werd aan de Supreme Court.

De Supreme Court stelde echter het beginsel van testeervrijheid meer centraal en kende de voorzieningen toe zoals die waren vastgesteld door de District Judge. Deze gang van zaken legt de achilleshiel van discretionaire aanspraken bloot. Een nadeel is namelijk dat oor- delen van verschillende rechters uiteen kunnen lopen. Waar de ene rechter oordeelde dat geen enkele voorziening getroffen hoefde te worden, verstrekte de ander 163.000 pond uit een nalatenschap van 486.000 pond.

Een mogelijkheid om tot meer eensgezindheid te komen over de manier waarop met dergelijke aanspraken wordt omgegaan, wordt geboden door Lady Hale. Zij stelt in haar commentaar op de uitspraak dat rechters nauwelijks aangeven welke factoren voor hen doorslaggevend zijn bij een besluit tot toekenning van een provision, terwijl hier toch vele verschillende redenen voor kunnen zijn. Denkbaar is het idee dat bezit in de familie moet blijven, het idee om te zorgen voor naasten die behoefte hebben aan een voorziening, maar ook het idee dat een persoon het verdiend heeft om een voorziening te krijgen vanwege zijn zorg voor de overledene of zijn bijdrage aan het opbouwen van diens vermogen kan ten grondslag liggen aan een overtuiging dat de wensen van de erflater doorkruist moeten worden. ${ }^{24}$ Meer inzicht in deze factoren kan meer sturing bieden aan rechters bij het invullen van de discretionaire bepalingen. Het is dan ook een gemiste kans dat de Supreme Court hierover niet meer duidelijkheid heeft gegeven.

\section{Vergelijking met de 'andere wettelijke rechten' uit Boek 4 BW}

Wanneer het Engelse systeem vergeleken wordt met het Nederlandse systeem, blijken de andere wettelijke rechten uit Boek 4 van het Burgerlijk Wetboek (BW) nog het meest te lijken op de voorzieningen die gevraagd kunnen worden op grond van de Inheritance Act 1975. Een vergelijking tussen beide systemen mag dan ook niet ontbreken.

Het valt op dat de aanspraken in Engeland flexibeler zijn dan de Nederlandse andere wettelijke rechten van Boek 4 BW. Bescherming van nabestaanden in complexe situaties die voortvloeien uit het toegenomen aantal echtscheidingen, stiefrelaties en kinderen die buiten huwelijk geboren worden, vindt dan ook gemakkelijker plaats in het Engelse systeem. Meer personen komen daar immers in aanmerking voor een beroep op voorzieningen, terwijl ook de omvang van hun aanspraken afhangt van de omstandigheden van het geval. Ook kan de rechter deze uitspraken in verschillende vormen toekennen. Hij is in tegenstelling tot de Nederlandse rechter niet gehouden een voorziening in een bepaald geval per se in de vorm van bijvoorbeeld een som ineens of een vruchtgebruik toe te kennen.

Een vergelijking met het Engelse systeem brengt dan ook de rigiditeit van de andere wettelijke rechten in beeld. Zijn er geen uitzonderingssituaties denkbaar

24. Ibid., r.o. 49 e.v. 
waarin de rechten van erfgenamen of legatarissen zouden moeten prevaleren boven wat de andere wettelijke rechten voorschrijven? Is werkelijk een beperking van de testeervrijheid gewenst als de erflater zijn gehandicapte kind voorrang verleent boven zijn tweede echtgenoot met wie hij op hoge leeftijd in een huwelijksgoederenstelsel van koude uitsluiting trouwde? Zou het meerderjarige kind dat zich onredelijk gedroeg tegenover de erflater naast zijn legitieme portie ook nog geld moeten kunnen eisen voor werk dat hij tijdens zijn meerderjarigheid voor hem verricht heeft?

\section{Conclusie}

Hoewel testeervrijheid in Engeland een prominentere positie inneemt dan in de systemen van continentaal West-Europa, worden nabestaanden toch beschermd indien voor hen geen reasonable financial provision aanwezig is. Deze bescherming bestaat niet uit een vaste aanspraak zoals de legitieme portie, maar hangt af van de omstandigheden van het geval. Dat zo'n systeem gepaard gaat met uitdagingen omtrent de afweging van relevante factoren volgt duidelijk uit de gang van zaken in Ilott v. Mitson. De rechter zal duidelijk aan moeten geven welke beginselen ten grondslag liggen aan gemaakte keuzes om in de loop der tijd meer inzicht te krijgen in de verhoudingen tussen deze beginselen. Een systeem waarin dat gebeurt, biedt meer flexibiliteit in het zoeken naar een balans tussen testeervrijheid en bescherming van nabestaanden dan een systeem met (alleen) een legitieme portie. 